\title{
Hiperidricidade: uma desordem metabólica
}

\author{
Hyperhydricity: a metabolic disorder
}

\author{
Andréa Guimarães Vieira de Vasconcelos ${ }^{\mathrm{I}}$ Lais Ferreira Tomas ${ }^{\mathrm{II}}$ \\ Terezinha Rangel Camara ${ }^{\text {III }}$ Lilia Willadino ${ }^{\text {IV }}$
}

\section{- REVISÃO BIBLIOGRÁFICA -}

\section{RESUMO}

A hiperidricidade, anteriormente chamada vitrificação, é considerada uma desordem fisiológica, bioquímica e morfológica decorrente do acúmulo anormal de água no interior das células e tecidos. As plantas cultivadas in vitro estão, indubitavelmente, sob contínua condição de estresse, os quais resultam em alterações metabólicas características do estresse oxidativo. Anatomicamente, plantas ou brotos afetados frequentemente apresentam-se inchados, com coloração verde claro, folhas translúcidas e com aparência de vidro, baixa relação número de células/área celular e hipolignificação. Alterações fisiológicas que ocorrem nas principais vias metabólicas, incluindo fotossíntese, respiração e transpiração, resultam em redução de eficiência dessas vias metabólicas. Os distúrbios morfológicos, fisiológicos e bioquímicos são desencadeados por fatores físicos, relacionados ao ambiente dos recipientes de cultivo $e$ consistência do meio de cultura ou por fatores químicos como os componentes do meio de cultura, em especial dos reguladores de crescimento em altas concentrações. A hiperidricidade ocorre em vários níveis de severidade, chegando a resultar na perda irreversível da capacidade morfogênica e o estabelecimento de um estado neoplásico das células, no entanto, na maioria dos casos, a hiperidricidade é considerada reversível. Esta revisão foca o conhecimento atual sobre o fenômeno da hiperidricidade abordando aspectos morfológicos, fisiológicos, bioquímicos e a reversibilidade do processo.

Palavras-chave: brotos translúcidos, condição de cultivo, distúrbio fisiológico, problemas no cultivo in vitro, vitrificação.

\section{ABSTRACT}

The hyperhydricity, formerly called vitrification, is considered a physiological, biochemistry and morfologic disorder due to abnormal accumulation of water inside the cells and tissues. Plants grown in vitro are undoubtedly under continuous stress condition which results in metabolic changes characteristic of oxidative stress. Anatomically plants or shoots affected often become swollen, with pale green, translucent sheets, glass-like, low relative number of cells / cell area and hipolignification. Physiological changes occur in major metabolic pathways including photosynthesis, respiration and transpiration resulting in reduced efficiency of these metabolic pathways. Morphological, physiological and biochemical disorders are triggered by physical factors related to the environment of cultivation vessels and consistency of the culture medium or by chemical factors such as culture medium components, especially the growth regulators in high concentrations. The hyperhydricity occurs at various levels of severity, reaching result in irreversible loss of morphogenic capacity and the establishment of a state of neoplastic cells, however, in most cases hyperhydricity is considered reversible. This review focuses on the current knowledge about the phenomenon of hyperhydricity addressing morphological, physiological, biochemical, and reversibility of the process.

Key words: translucent shoots, culture condition, physiological disorders, in vitro culture problems, vitrification.

\footnotetext{
IPrograma de Pós-graduação em Zootecnia, Universidade Federal Rural de Pernambuco (UFRPE), Rua Dom Manoel de Medeiros s/n, 52171-900, Recife, PE, Brasil.

IIDepartamento de Agronomia, UFRPE, Recife, PE, Brasil.

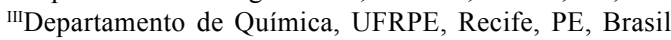

IV Departamento de Biologia UFRPE, Recife, PE, Brasil. E-mail: willadino.lilia@gmail.com. Autor para correspondência.
} 


\section{INTRODUÇÃO}

A hiperidricidade, anteriormente chamada vitrificação, é definida como o estado fisiológico em que a planta apresenta um acúmulo anormal de água no interior das células e tecidos e, de uma maneira geral, resulta em um aspecto translúcido característico. É uma das principais anormalidades observadas em plantas cultivadas em meio semi-sólido ou líquido, especialmente em partes aéreas cultivadas em biorreatores (FERNADEZ-GARCIA et al., 2011). As plantas ou brotos afetados frequentemente apresentamse inchados, com coloração verde claro, folhas translúcidas e com aparência de vidro; as folhas se apresentam também alongadas, túrgidas e frágeis, sendo, provavelmente, consequência da difusão passiva da água para dentro dos tecidos ou um fenômeno ativo relacionado a um distúrbio no processo metabólico da planta (FRANCK et al., 2001; KEVERS et al., 2004). Os distúrbios fisiológicos podem ocorrer em vários níveis de severidade e são dependentes, também, do genótipo da planta (KHARRAZI et al., 2011). As brotações de culturas que demonstram sintomas leves frequentemente crescem mais rapidamente do que o normal e podem mostrar altas taxas de brotações axilares. Essa vantagem, entretanto, é perdida em condições mais severas de hiperidricidade (SANTOS et al., 2001). O fenômeno da hiperidricidade pode evoluir irreversivelmente para a perda da capacidade regenerativa do tecido (GASPAR et al., 2000).

Plantas que apresentam hiperidricidade são caracterizadas por baixos níveis de lignina e celulose (KEVERS et al., 1996; 2004); baixa resistência de parede celular (KEVERS \& GASPAR, 1986; FRANCK et al., 2004); baixo teor de clorofila e porcentagem de massa seca (PARK et al., 2004; FRANCK et al., 2004); folhas entumescidas e quebradiças (DEBERGH, 1983; ZIV et al., 1983); alteração estomática; baixa deposição de cera (MAJADA et al., 2001); e reduzida taxa de sobrevivência em condições autotróficas (MAJADA et al., 2001).

A hiperidricidade é um dos problemas mais importantes na micropropagação industrial de plantas (FERNADEZ-GARCIA et al., 2011), podendo acarretar perdas de até $70 \%$ de partes aéreas ou plantas na micropropagação comercial (DEWIR et al., 2006; FRÁGUAS et al., 2009). A despeito das perdas causadas pela hiperidricidade na micropropagação de plantas, ainda existem muitas questões a serem esclarecidas sobre a causa da ocorrência desse fenômeno. Numerosas hipóteses têm sido formuladas para explicar a hiperidricidade, mas permanece uma lacuna sobre quais são os sinais responsáveis, ou quais deles são afetados pelo seu desenvolvimento (PIQUERAS et al.,
2002). A suscetibilidade e os sintomas podem variar entre espécies (GASPAR et al., 1987) ou mesmo entre cultivares de uma mesma espécie (PEREZ-TORNERO et al., 2001; FRÁGUAS et al., 2009). Esta revisão foca o conhecimento atual sobre o fenômeno da hiperidricidade, abordando aspectos morfológicos, fisiológicos, bioquímicos e a reversibilidade do processo.

\section{Aspectos morfológicos}

Plantas e partes aéreas hiperídricas apresentam caules e folhas túrgidas, espessas, enrugadas, torcidas, translúcidas, rígidas e facilmente quebráveis (PICOLI et al., 2001; KEVERS et al., 2004). As partes aéreas apresentam encurtamento dos entrenós e uma aparência morfológica que sugere excesso de água (Figura 1). Muitos autores associam a coloração verde escura com a hiperidricidade (BORKOWSKA \& MICHALEZUK, 1987), enquanto outros caracterizam os tecidos e órgãos hiperídricos por serem translúcidos e perderem a clorofila (PARK et al., 2004). Os caules exibem hipertrofia do parênquima cortical e medular, hipolignificação, diminuição ou aspecto anormal do sistema vascular, vasos e traqueídes pouco lignificados (KEVERS \& GASPAR, 1986; KEVERS et al., 2004). As folhas hiperídricas possuem um tecido epidérmico imperfeito com uma fina cutícula intermitente e pouca ou nenhuma cera epicuticular (GASPAR, 1991; MAJADA et al., 2001). Em muitos casos, o tecido paliçádico é inexistente ou drasticamente reduzido. O mesofilo tem aspecto esponjoso e é bastante vacuolado com grandes espaços intercelulares. Observa-se uma baixa relação número de células/área celular, o que sugere que o espessamento foliar seja resultante do incremento no tamanho das células do mesofilo (VIEITEZ et al., 1985; KEVERS et al., 2004). PICOLI et al. (2001) descreveram distintos padrões de desenvolvimento das "folhas hiperídricas compactas" e "folhas hiperídricas lacunosas". As folhas compactas desenvolvem uma camada de células paliçádicas levemente diferenciadas, enquanto que nas folhas lacunosas a diferenciação em paliçada é reduzida e o espaço intercelular e a extensão do parênquima esponjoso aumentam. KEVERS \& GASPAR (1986) demonstraram que o excesso de água nesses tecidos localiza-se no espaço apoplástico e que o protoplasto contém menos água. Para outros autores, a decomposição da lamela média, resultando na perda do contato célula-célula, é apontada como a causa do aumento do espaço intercelular (LESHEM, 1983; WERKER \& LESHEM, 1987). Deformações na parede celular das células guarda estão intimamente correlacionadas com a hiperidratação foliar, infligindo 


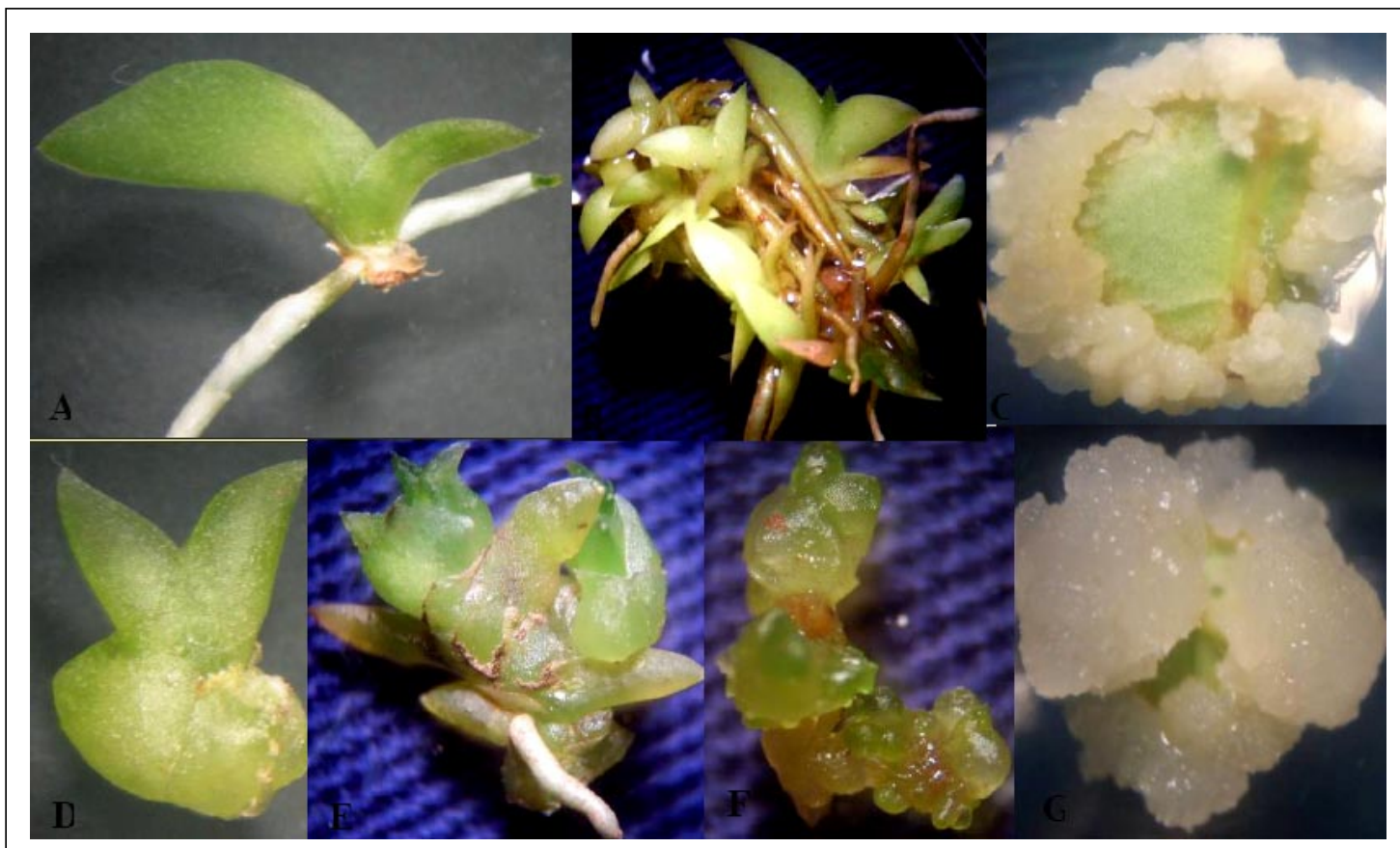

Figura 1 - Plântulas e brotos de orquídea (Rodrigesia sp.) provenientes de germinação assimbiótica em meio MS e calos de café conilon (Coffea canephora Pierre Ex-Froehner) provenientes de discos foliares após 35 dias de inoculação do explante. (A) Plântula normal; (B) Brotação não hiperídrica; (C) Calo embriogênico (não hiperídrico) em meio MS com 1,5(M de BAP e 1,0(M de 2,4-D - aspecto friável e granuloso; (D) Plântula hiperídrica; (E e F) Brotações com distintos graus de hiperidricidade; (G): calo hiperídrico em meio MS com 1,0(M de BAP e 4,0(M de 2,4-D - aspecto aquoso e vítreo.

uma morfogênese anormal da parte aérea. Estômatos levemente maiores e com células guarda drasticamente deformadas, refletindo possíveis alterações em toda morfologia estomática, foram observados em folhas hiperídricas de berinjela (PICOLI et al., 2001). Em cravo Dianthus caryophyllus, também foram constatados estômatos malformados em plantas hiperídricas (MAJADA et al., 2001). A causa dos danos na parede das células que circundam o orifício estomático em folhas hiperídricas pode ser resultante de uma divisão defeituosa das células-mãe do estômato (ZIV \& ARIEL, 1994). Essas deformações podem ser decorrentes de alterações estruturais nas células guarda, seguidas de modificações na composição química da parede celular (PICOLI et al., 2001). Imagens de estômatos anormais de folhas de cravo (Dianthus caryofilus L. cv. Ceris royallete) revelaram paredes celulares com menos calose e sem a típica orientação das microfibrilas de celulose. Esse tipo de modificação estrutural acarretou a perda da elasticidade da parede celular (ZIV \& ARIEL, 1994), os estômatos das folhas hiperídricas permaneceram abertos e não responderam ao escuro, ao ácido abscísico (ABA), à alta concentração de $\mathrm{Ca}^{2+}$ e a soluções hipertônicas (WARDLE et al., 1979; ZIV,
1991). A estrutura e o funcionamento estomático podem proporcionar uma avaliação mais precisa da hiperidricidade das plantas do que apenas a aparência externa das folhas (ZIV \& ARIEL, 1994). A presença de estômatos não funcionais pode ser considerada a maior causa da perda de água e morte dos brotos durante a aclimatização de plantas hiperídricas (ZIV, 1991). Brotos hiperídricos apresentam menor formação de raízes, ou não enraízam e, em geral, não sobrevivem à aclimatização e, quando sobrevivem, originam plantas malformadas. A hiperidricidade ocorre também em calos (JOYCE et al., 2003) e embriões somáticos (PICOLI et al., 2001). Calos hiperídricos têm aspecto vítreo e aquoso (Figura 1) e, em geral, não possuem capacidade regenerativa. Esses calos são constituídos de células do parênquima sem elementos do xilema (KEVERS et al., 2004). As aberrações anatômicas nos tecidos hiperídricos estão relacionadas com diversas características fisiológicas e bioquímicas, algumas das quais comentadas a seguir.

\section{Aspectos fisiológicos e bioquímicos}

A hiperidricidade é uma das principais anomalias que tem recebido atenção especial nos 
últimos anos, tendo sido observada a interação simultânea de diversos fatores, interferindo nas principais vias metabólicas como fotossíntese, respiração e transpiração (ZIV, 1991). O aumento dos teores de $\mathrm{H}_{2} \mathrm{O}_{2}$, da peroxidação de lipídios (com o aumento do teor de malondialdeído-MDA) e da atividade de enzimas do sistema antioxidativo refletem a relação entre o estresse oxidativo e a hiperidricidade (SAHER et al., 2004; SAHER et al., 2005b). As partes aéreas cultivadas em estado hiperídrico eventualmente adaptam-se para sobreviver, preservando sua homeostase redox e minimizando o gasto de energia em detrimento da diferenciação celular (FRANCK et al., 2001). Por outro lado, pode ocorrer a perda irreversível da capacidade morfogênica e o estabelecimento de um estado neoplásico das células, similar à formação do câncer em animais, culminando com necrose do meristema apical (GASPAR et al., 1998; GASPAR et al., 2000).

A hiperidricidade provoca alterações nas atividades das enzimas ácido 1-aminociclopropano-1carboxílico sintase (ACC-sintase), fenilalanina amonioliase (PAL) e peroxidases. A ACC-sintase é responsável pela conversão da $S$-adenosilmetionina (SAM) em ACC, que é oxidado a etileno. Já a PAL é uma enzima chave na síntese de lignina, o que explica a ocorrência de falha na biossíntese desse polímero em tecidos hiperídricos (PIQUERAS et al., 2002). A água que forma uma camada em volta das células pode limitar a difusão do oxigênio para elas, causando hipoxia, e induzir a formação de peróxido de hidrogênio ( $\mathrm{H} \mathrm{O}$ ) em níveis tóxicos, resultando em estresse oxidativo (SAHER et al., 2004). A hipoxia, à medida que afeta o processo respiratório, reduz a disponibilidade de ATP produzido nas mitocôndrias por meio da fosforilação oxidativa (SAHER et al., 2005a). A avaliação do metabolismo energético de partes aéreas hiperídricas tem demonstrado também uma queda na produção de energia química na forma de nucleotídeos de piridina, NADPH e NADH, além de ATP. Essa diminuição no metabolismo energético está associada a um menor teor de clorofila e a uma menor atividade de enzimas da via oxidativa das pentoses-fosfato (OPP) e da glicólise (FRANCK et al., 2001). Medidas da fluorescência de clorofila permitiram constatar uma discreta redução do processo fotoquímico do fotossistema II (FS-II) de folhas hiperídricas, quando comparadas com folhas normais, indicando que a menor capacidade fotossintética deve-se mais propriamente ao menor teor de clorofila do que a uma disfunção do aparato fotossintético (FRANCK et al., 2001; SAHER et al., 2005a). O reduzido conteúdo de celulose (GASPAR, 1991; MAJADA et al., 2001) ocorre em função da baixa relação $\mathrm{C} / \mathrm{N}$ - que favorece a síntese de aminoácidos em detrimento da síntese do polissacarídeo - e da alta atividade de peroxidases básicas, que está relacionada com um elevado catabolismo de auxinas (JOYCE et al., 2003). A hiperidricidade caracteriza-se pelo baixo conteúdo de proteína (FRÁGULA et al., 2009), elevado conteúdo de citocininas e composição iônica alterada (KATAEVA et al., 1991; PICOLI et al., 2001; KEVERS et al., 2004), esta última decorrente da reduzida capacidade de absorção de nutrientes, como constatado em explantes de cravo hiperídricos (DANTAS et al., 2001).

Fatores indutores da hiperidricidade

As partes aéreas propagadas in vitro estão sob contínua condição de estresse (GASPAR et al., 2002; KEVERS et al., 2004) e vários processos metabólicos induzidos pelo estresse geram o estresse oxidativo. Entende-se por estresse oxidativo o desequilíbrio na relação entre compostos antioxidantes e compostos pro-oxidantes, a favor destes últimos, levando ao aumento do nível de espécies reativas de oxigênio (ROS): o ânion radical superóxido $\left(\mathrm{O}_{2}{ }^{-}\right)$, o peróxido de hidrogênio $\left(\mathrm{H}_{2} \mathrm{O}_{2}\right)$ e os radicais hidroxila ('OH) e hidroperoxila ( $\mathrm{ROO}^{\circ}$ ). As ROS provocam danos aos ácidos nucleicos, proteínas e lipídios (PICOLI et al., 2001; GASPAR et al., 2002; ORCHATT et al., 2002). $\mathrm{O}$ acúmulo de ROS e a indução do estresse oxidativo foram observados na maioria dos tecidos hiperídricos descritos na literatura, entretanto, pouco é conhecido sobre a origem do estresse oxidativo induzido em tecidos hiperídricos (FERNANDEZ-GARCIA et al., 2011).

Há relatos de que a maior atividade de peroxidase, em brotações hiperídricas de diversas espécies, pode estar relacionada ao etileno (FRANCK et al., 2004). Outros autores também descreveram um aumento no etileno, em tecidos hiperídricos, e relacionaram o aumento desse hormônio ao aumento da produção de peróxido de hidrogênio e, consequentemente, a um aumento na atividade da peroxidase (SAHER et al., 2004).

Alguns trabalhos destacaram que a hiperidricidade pode ser desencadeada pelo desequilíbrio dos componentes do meio de cultura, em especial dos reguladores de crescimento (KATAEVA et al., 1991; OLIVEIRA et al., 1997; JOYCE et al., 2003), sobretudo devido à presença de altas concentrações de citocinina e/ou auxina (PICOLI et al., 2001)

Alguns autores sugeriram que, além do meio de cultura, as condições atmosféricas do ambiente de cultivo induziram a formação de tecidos hiperídricos (KEVERS et al., 2004). O ambiente do cultivo in vitro convencional apresenta características peculiares, tais como: alto potencial da água no meio de cultura, alta 
umidade relativa no recipiente de cultivo, temperatura constante, baixa densidade de fluxo de fótons, ampla flutuação na concentração diurna de $\mathrm{CO}_{2}$ e ausência de microrganismos. Tal condição de estresse frequentemente ocasiona o surgimento de desordens morfológicas e fisiológicas, dificultando o desenvolvimento das plantas cultivadas in vitro (KOZAI et al., 1997). Um dos fatores ambientais de maior importância na indução da hipridricidade em plantas cultivadas in vitro é a alta umidade relativa (UR), resultante da ineficiente difusão dos gases entre a atmosfera interna e externa aos recipientes de cultivo. A alta UR implica reduzida taxa transpiratória e excessiva absorção de água pelos tecidos vegetais com a formação de novas células, que logo se tornam túrgidas (PICOLI et al., 2001). A redução de apenas 5\% na UR é suficiente para reverter e até evitar a hiperidricidade, enquanto que uma UR de $100 \%$ induziu $100 \%$ de hiperidricidade em partes aéreas de cravo (SAHER et al., 2005b).

A consistência do meio de cultura, bem como o tipo e a concentração do agente gelificante também podem contribuir para evitar ou promover a hiperidricidade (DEBERGH, 1983; ZIV et al., 1983). Parece haver uma relação inversamente proporcional entre a concentração de ágar no meio nutritivo e o grau de hiperidricidade dos tecidos cultivados in vitro. A frequência de hiperidricidade é maior em culturas mantidas em meio líquido, provavelmente em função de os tecidos submersos apresentarem marcado estresse oxidativo, com elevadas concentrações de espécies reativas de oxigênio associado a uma mudança na atividade das enzimas anti-oxidantes (ZIV, 2005). Em algumas plantas, brotações normais cultivadas em meio semi-sólido ficam totalmente vitrificadas quando são transferidas para um meio de cultivo líquido, como verificado na cultura da palma forrageira em cultivo no sistema de imersão temporária(VASCONCELOS etal., 2010).

Vários autores demonstraram que o aumento da concentração de ágar pode reverter a hiperidricidade, mas diminui drasticamente a taxa de propagação (DEBERGH, 1983; ZIV et al., 1983). Acredita-se que o estado físico do meio pode afetar a difusão dos reguladores de crescimento e dos nutrientes (BORNMAN \& VOGELMAN, 1984) e que o ágar pode interagir quimicamente com substâncias solúveis do meio de cultura e interferir na disponibilidade delas (BRAND, 1993).

Alternativas de controle

O processo de hiperidricidade é geralmente considerado reversível. Isso não significa que folhas hiperídricas, uma vez completamente formadas e maduras, revertam à sua estrutura normal, mas que novas brotações ou folhas recém formadas em partes aéreas hiperídricas, após serem transferidas para meio ou ambiente não propício à ocorrência desse fenômeno, podem ter uma morfologia e anatomia similar a das plantas normais (KEVERS et al., 2004). Vários métodos e sistemas de cultivo que reduzem ou controlam o excesso de água na atmosfera interna dos tubos de cultura vêm sendo desenvolvidos. O tipo de fechamento dos recipientes é outro fator de controle da UR. O uso de tampas com filtros de $0.2 \mu \mathrm{m}$ (MAJADA et al., 1997), ou de membranas permeáveis ao ar associadas, ou não, a sistema de ventilação forçada (ZOBAYED et al., 2001), são exemplos de alternativas para controlar a UR e evitar a hiperidricidade. O emprego de meio líquido associado a sistemas de aeração permite evitar a hiperidricidade e aumentar a taxa de micropropagação (DANTAS et al., 2001). Os biorreatores de imersão temporária constituem um sistema de micropropagação que alia as vantagens do meio líquido a um modelo de aeração que evita o ressecamento do meio de cultura.

Outros métodos empregados para evitar a hiperidricidade incluem modificações no meio de cultura, tais como aumento no teor de carboidratos (ZIMMERMAN \& COBB, 1989; WHITEHOUSE et al., 2002), adição de peptona (SATO et al., 1993), hidrolisados de ágar (NAIRN et al., 1995), ou uma alta relação $\mathrm{NH}^{4+}$ / $\mathrm{NO}^{3-}($ BORNMAN \& VOGELMANN, 1984).

Os efeitos indesejáveis de uma condição hiperídrica podem ser minimizados mediante a redução da concentração de reguladores de crescimento, sobretudo das citocininas. No que se refere à ação de citocininas, o efeito deletério também pode ser reduzido com a aplicação de pulsos de curta duração com altas concentrações de 6-benzilaminopurina (BAP) (BORNMAN \& VOGELMANN, 1984), ou com a utilização da topolina, citocinina natural, como alternativa ao BAP (AREMU et al., 2012).

\section{CONCLUSÃO}

A hiperidricidade é consequência das condições do cultivo in vitro, que resultam, em última análise, em estresse oxidativo. A hiperidricidade é um processo reversível e pode ser evitado mediante controle e ajuste de variáveis que incluem a umidade relativa no interior do frasco; trocas com o ambiente de vapor d'água e gases, como etileno; concentração e tipo do agente gelificante; concentração e tipo de reguladores de crescimento. Recentemente, a topolina, citocinina natural, é apontada como perspectiva para evitar desordens fisiológicas em material cultivado in vitro em presença de BAP. 


\section{REFERÊNCIAS}

AREMU, A.O. et al. Topolins: A panacea to plant tissue culture challenges? Plant Cell Tissue \& Organ Culture, v.108, p.1-16, 2012. Disponível em: <http://www.springerlink.com/ content/et40280134181113/>. Acesso em: 02 jan. 2012. doi: 10.1007/s11240-011-0007-7.doi 10.1007/s11240-011-0007-7.

BORKOWSKA, B.; MICHALEZUK, L. The physiology disorders of sour cherry cultures: necrosis and vitrification. Acta Horticulturae, v.212, p.235-237, 1987.

BORNMAN, C.H.; VOGELMANN, T.C. Effect of rigidity of gel medium on benzyladenine - induced adventious bud formation and vitrification in vitro in Picea abies. Physiologia Plantarum, v.61, p.505-512, 1984. Disponível em: <http:// onlinelibrary.wiley.com/doi/10.1111/j.13993054.1984.tb06364.x/citedby>. Acesso em: 10 jun. 2011. doi:10.1111/j.1399-3054.1984.tb06364.x.

BRAND, M.H. Agar and ammonium nitrate influence hyperhydricity, tissue nitrate and total nitrogen content of serviceberry (Amelanchier arborea) shoots in vitro. Plant Cell Tissue and Organ Culture, v.35, p.203-209, 1993. Disponível em: <http://www.springerlink.com/content/ x863j24w13504563>. Acesso em: 5 maio, 2011. doi:10.1007/ BF00037271.

DANTAS, A.K. et al. Mineral nutrition in carnation tissue cultures under different ventilation conditions. Plant Growth Regulation, v.33, p.237-243, 2001. Disponível em: <http:// www.springerlink.com/content/p57vwv6373147g65/>. Acesso em: 30 maio, 2011. doi:10.1023/A:1017542106252.

DEBERGH, P.C. Effects of Agar brand and concentration on the tissue culture medium. Physiologia Plantarum, v.59, p.270276, 1983. Disponível em: <hptt://onlinelibrary.wiley.com/>. Acesso em: 10 jun. 2011. doi: 101111/ j.13993054.1983.tb00770.x.

DEWIR, Y.H. et al. Lipid peroxidation and antioxidant enzyme activities of Euphorbia millii hyperhydric shoots. Environmental and Experimental Botany, v.58, p.93-99, 2006. Disponível em: <http://www.sciencedirect.com/science/ article/pii/S0098847205001140>. Acesso em: 3 mar. 2011. doi:10.1016/j.envexpbot.2005.06.019.

FERNANDEZ-GARCIA, N. et al. ROS as biomarkers of hiperhydricit. In: GUPTA, D. Reactive oxygen species and antioxidants in higher plants. London Local: Sciences Publishers, 2011. Cap.12, p.249-272.

FRÁGUAS, C.B. et al. Benzilaminopurina e ácido naftaleno acético na indução e multiplicação in vitro de gemas de abacaxizeiro da cultivar 'IAC Gomo-de-mel'. Ciência Rural, v.39, n.6, p.994-1000, 2009. Disponível em: <http:// submission.scielo.br/index.php/cr/article/view/7351>. Acesso em: 10 jun. 2011. doi: 10.1590/S0103-84782009000600008.

FRANCK, T. et al. Are hyperhydric shoots of Prunus avium L. energy deficient. Plant Science, v.160, p.1145-1151, 2001. Disponível em: <http://hdl.handle.net/2268/3413>. Acesso em: 22 maio, 2011. doi:10.1016/S0168-9452(01)00362-4.

FRANCK, T. et al. Hyperhydricity of Prunus avium L. shoots cultured on gelrite: a controlled stress response. Plant
Physiology and Biochemistry, v.42, p.519-527, 2004. Disponível em: $<$ http://hdl.handle.net/2268/3078>. Acesso em: 18 maio, 2011. doi:10.1016/j.plaphy.2004.05.003.

GASPAR, T. Vitrification in micropropagation. In: BAJAJ, Y.P.S. (Ed.). Biotechnology in agriculture and forestry: High-tech and micropropagation I. Berlin: Springer, 1991. p. 116-126.

GASPAR, T. et al. Atypical metabolism and biochemical cycles imposing the cancerous state on plant cells. Plant Growth Regulation, v.24, p.135-144, 1998. Disponível em: <http:// www.springerlink.com/content/q2450x555u2j28k6/.> Acesso em: 14 jun. 2011. doi: 10.1023/A:1005972924568.

GASPAR, T. et al. Concepts in plant stress physiology. Applications to plant tissue cultures. Plant Growth Regulation, v.37, p.263-285, 2002. Disponível em: <http:// www.springerlink.com/content/k655317888w75064/>. Acesso em: 10 jun. 2011. doi 10.1023/A:1020835304842.

GASPAR, T. et al. In vitro plant recalcitrance loss of plant organogenic totipotency in the course of In vitro neoplastic progression. In vitro Cellular \& Developmental Biology Plant, v.36, p.171-181, 2000. Disponível em: <http:// www.springerlink.com/content/1054-5476/36/3/>. Acesso em: 18 jun. 2011. doi: $10.1007 / \mathrm{s} 11627-000-0033-3$.

GASPAR, T. et al. Vitification: morphological, physiological and ecological aspects. In: BONGA, J.M.; DURZAN, D.J. (Ed.). Cell and tissue culture in forestry. Dordrecht: Martinus Nijhoff Publishers, 1987. p.152-166.

JOYCE, S.M. et al. Stress and aberrant phenotypes in in vitro culture. Plant Cell, Tissue and Organ Culture, v.74, p.103121, 2003. Disponível em: <http://www.springerlink.com/ content/t472248x60064262/>. Acesso em: 18 jun. 2011. doi:10.1023/A:1023911927116.

KATAEVA, N.V.et al. Effect of applied and internal hormones on vitrification and apical necrosis of different plants cultured in vitro. Plant Cell, Tissue and Organ Culture, v.14, p.31-40,1991. Disponível em: <http://www.springerlink.com/ content/x575708r12881k48/>. Acesso em: 15 jun. 2011. doi:10.1007/BF00041283.

KHARRAZI, M. et al. In Vitro Culture of Carnation (Dianthus caryophyllus L.) Focusing on the Problem of Vitrification. Journal of Biolology and Environmental Science, v.5, p.1-6, 2011. Disponível em: <http://jbes.uludag.edu.tr/ PDFDOSYALAR/13/mak01.pdf>. Acesso em: 18 jun. 2011.

KEVERS, C.; GASPAR, T. Vitrification of carnation in vitro: changes in water content, extracelular space, air volume, and ion levels. Physiologie Vegètale, v.244, p.647-653, 1986.

KEVERS, C. et al. Habituation of plant cells does not mean insensivity to plant growth regulators. In vitro Cellular \& Developmental Biology - Plant, v.32, p.204-206, 1996. Disponível em: <http://www.springerlink.com/content/ t4350k4352403645>. Acesso em: 5 jan. 2011. doi:10.1007/ BF02822767.

KEVERS, C. et al. Hyperhydricity of micropropagated shoots: at typically stress-induced change of physiological state. Plant Cell, Tissue and Organ Culture, v.77, p.181-191, 2004. 
Disponível em: <http://www.springerlink.com/content/ w371477125845757/>. Acesso em: 5 jan. 2011. doi:10.1023/ B:TICU.0000016825.18930.e4.

KOZAI, T. et al. Enviromental control for the large-scale production of plants through in vitro techniques. Plant Cell, Tissue and Organ Culture, v.51, p.49-56, 1997. Disponível em: <http://www.springerlink.com/content/ku55k63757686255>. Acesso em: 12 jun. 2011. doi:10.1023/A:1005809518371.

LESHEM, B. Growth of carnation meristems in vitro: anatomical structure of abnormal plants and the effect of agar concentration in the medium on their formation. Annals of Botany, v.52, p.413-415, 1983. Disponível em: $<\mathrm{http}: / /$ aob.oxfordjournals.org/content $/ 52 / 3 / 413$.full.pdf $>$. Acesso em: 3 abr. 2011

MAJADA, J.P. et al. The effect of ventilation on proliferation and hyperhydricity of Dianthus caryophyllus L. In vitro Cellular \& Developmental Biology - Plant, v.33, p.6269, 1997. Disponível em: <http://www.springerlink.com/ content/gj0777q678460008/>. Acesso em: 30 jul. 2010. doi:10.1007/s11627-997-0042-6.

MAJADA J.P. et al. Air exchange rate affects the in vitro developed leaf cuticle of carnation. Science Horticulturae, v.87, p.121-130, 2001. Disponível em: <http:// www.ingentaconnect.com/content/els/03044238/2001/ 00000087/00000001/art00162>. Acesso em: 19 jul. 2010. doi:10.1016/S0304-4238(00)00162-X.

NAIRN, B.J. et al. Identification of an agar constituent responsible for hydric control in micropropagation of radiata pine. Plant Cell, Tissue and Organ Culture, v.43, p.1-11, 1995. Disponível em: <http://www.springerlink.com/content/ q215628601528452>. Acesso em: 01 dez. 2010. doi:10.1007/ BF00042665.

ORCHATT, S.J. et al. The hyperhydricity of in vitroregenerants of grass pea (Lathyrus sativus L.) is linked with an abnormal DNA content. Journal of Plant Physiology, v.159, p.1021-1028, 2002. Disponível em: <http:// www.ingentaconnect.com/content/urban/271/2002/00000159/ 00000009/art00682>. Acesso em: 24 set. 2010. doi:10.1078/ 0176-1617-00682.

OLIVEIRA, A.K.D. et al. Endogenous plant growth regulators in carnation tissue cultures under different conditions of ventilation. Plant Growth Regulation, v.22, p.169-174, 1997. Disponível em: <http://www.springerlink.com/content/ x1853713r5167087/>. Acesso em: 28 mar. 2011. doi:10.1023/ A:1005870832508.

PARK, S.W. et al. Effect of sealed and vented gaseous microenvironment on hyperhydricity of potato shoots in vitro. Scientia Horticulturae, v.99, p.199-205, 2004. Disponível em: $<$ http://dx.doi.org.ez19. periodicos.capes.gov.br/10>. Acesso em: 28 mar. 2011. doi:1016/S0304-4238(03)00097-9.

PEREZ-TORNERO, O. et al. Control of hyperhidricity in micropropagated apricot cultivars. In vitro Cellular \& Developmental Biology - Plant, v.37, p.250-254, 2001. Disponível em: <http://aob.oxfordjournals.org/content/59/4 377.full.pdf + html . Acesso em: 28 mar. 2011. doi: 10.1007/ s11627-001-0044-8.
PICOLI, E.A.T. et al. Hyperhydricity in in vitro eggplant regenerated plants: structural characteristics and involvement of BiP (Binding Protein). Plant Science, v.160, p.857-868, 2001. Disponível em: <http://www.ingentaconnect.com/ content/els/01689452/2001/00000160/00000005/>. Acesso em: 28 mar. 2011. doi:10.1016/S0168-9452(00)00463-5.

PIQUERAS, A. et al. Polyamines and hyperhydricity in micropropagated carnation plants. Plant Science, v.62, p.671678, 2002. Disponível em: <http://www.ingentaconnect.com/ content/els/01689452/2002/00000162/00000005/art00007>. Acesso em: 28 mar. 2011. doi:10.1016/S0168-9452(02)00007-9.

SAHER, S. et al. Hyperhydricity in micropropagated carnation shoots: the role of oxidative stress. Physiologia Plantarum, v.120, p.152161, 2004. Disponível em: <http://onlinelibrary.wiley.com/doi/ 10.1111/j.0031-9317.2004.0219.x/full>. Acesso em: 24 abr. 2011. doi:10.1111/j.0031-9317.2004.0219.x.

SAHER, S. et al. Reducing properties, energy efficiency and carbohydrate metabolism in hyperhydric and normal carnation shoots cultured in vitro: a hypoxia stress. Plant Physiology and Biochemistry, v.43, p.573-582, 2005a. Disponível em: $<\mathrm{http}: / / \mathrm{hdl}$.handle.net/10261/19715>. Acesso em: $05 \mathrm{mar}$. 2011. doi: 10.1016/j.plaphy.2005.05.006.

SAHER, S. et al. Prevention of hyperhydricity in micropropagated carnation shoots by bottom cooling: implications of oxidative stress. Plant Cell, Tissue and Organ Culture, v.81, p.149-158, 2005b. Disponível em: $<$ http://www.springerlink.com/content/mhwp0142r314p570>. Acesso em: 26 fev. 2011. doi:10.1007/s11240-004-4043-4.

SANTOS, R.B. et al. Problemas no cultivo in vitro: cultura de tecidos. Lavras, M.G.: UFLA, 2001. V.9, p.79.

SATO, S. et al. Recovering vitrified carnation (Dianthus caryophyllus L.) shoots using Bacto-Peptone and its subfractions. Plant Cell Report, v.12, p.370-374, 1993. Disponível em: <http://www.springerlink.com/content/ kl31113h56142122>. Acesso em: 25 out. 2011. doi:10.1007/ BF00234695.

VASCONCELOS, A.G.V. et al. Cultura de tecidos vegetais: técnicas utilizadas para multiplicação acelerada da palma forrageira. In: FIGUEIREDO, M.V.B. et al. (Eds). Biotecnologia aplicada à agricultura. Brasília: EMBRAPA, 2010. p.678.

VIEITEZ, A.M. et al. Anatomical and chemical studies of vitrified shoots of chestnut regenerated in vitro. Physiologia Plantarum, v.65, p.177-184, 1985. Disponível em: <http:// onlinelibrary.wiley.com/doi/ $10.1111 /$ j. 1399 . 3054.1985.tb02379.x/ful>. Acesso em: 28 mar. 2011. doi:10.1111/j.1399-3054.1985.tb02379.x.

WARDLE, K. et al. Abscisic acid and the regulation of water loss in plantlets. Annals of Botany, v.43, p.745-752, 1979. Disponível em: <http://aob.oxfordjournals.org/content/43/6/ 745.short>. Acesso em: 28 mar.2011.

WERKER, E.; LESHEM, B. Structural changes during vitrification of carnation plantlets. Annals of Botany, v.59, p.377-385, 1987. Disponível em: <http://aob.oxfordjournals.org/ content/59/4/377>. Acesso em: 25 out. 2010 . 
WHITEHOUSE, A.B. et al. Control of hyperhydricity in Eucalyptus axillary shoot cultures grown in liquid medium. Plant Cell, Tissue and Organ Culture, v.71, p.245-252, 2002. Disponível em: <http://www.springerlink.com/content/ kj4046442g259073>. Acesso em: 25 out. 2010. doi:10.1023/ A: 1020360120020 .

ZIMMERMAN, T.W.; COBB, B.G. Vitrification and soluble carbohydrate levels in Petunia leaves as influenced by media, gelrite and sucrose concentration. Plant Cell Report, v.8, p.358-360, 1989. Disponível em: <http:// www.springerlink.com/content/n6201x137g851346/1989>. Acesso em: 28 mar. 2011. doi:10.1007/BF00716673.

ZIV, M.; ARIEL, T. Vitification in relation to stomatal deformation and malfunction in carnation leaves in vitro. In: LUMDSEN, P.J. et al. (Eds.). Physiology, growth and development of plants in culture. Netherlands: Kluwer Academic Publishers, 1994. p.142-154.

ZIV, M. Simple bioreactors for mass propagation plants. In vitro Cellular \& Developmental Biology - Plant, v.81, p.277-
285. 2005. Disponível em: <https://springerlink3.metapress.com/ content $/ \mathrm{m} 8 \mathrm{~h} 77 \mathrm{kq} 386671604>$. Acesso em: 25 out. 2010. doi: 10.1007/s11240-004-6649-y.

ZIV, M. Quality of micropropagated plants - vitification. In vitro Cellular \& Developmental Biology - Plant, v.27, p.64-69, 1991. Disponível em: <http://www.springerlink.com/ content/1054-5476/27/2/>. Acesso em: 25 out. 2010. doi: $10.1007 / \mathrm{BF} 02632130$.

$\mathrm{ZIV}$, M. et al. Factors influencing the production of hardened glaucous carnation plantlets in vitro. Plant Cell, Tissue and Organ Culture, v.2, p.55-60, 1983. Disponível em: http:// www.springerlink.com/content/p53n3t536t3762g0. Acesso em: 28 mar. 2011. doi:10.1007/BF00033553.

ZOBAYED, S.M.A. et al. Micropropagation of potato: evaluation of closed, diffusive and forced ventilation on growth and tuberization. Annals of Botany, v.87, p.53-59, 2001. Disponível em: <http://aob.oxfordjournals.org/content/87/1/ 53.short $>$. Acesso em: 25 out. 2010. doi:10.1006/ anbo. 2000.1299 . 